\title{
Guillain-Barré Syndrome: Natural history and prognostic factors: a retrospective review of 106 cases
}

\author{
Inés González-Suárez ${ }^{*}$, Irene Sanz-Gallego ${ }^{\dagger}$, Francisco Javier Rodríguez de Rivera ${ }^{\dagger}$ and Javier Arpa $^{\dagger}$
}

\begin{abstract}
Background: Guillain-Barre syndrome (GBS) is characterized by acute onset and progressive course, and is usually associated with a good prognosis. However, there are forms of poor prognosis, needing ventilatory support and major deficits at discharge. With this study we try to identify the factors associated with a worse outcome.

Methods: 106 cases of GBS admitted in our hospital between years 2000-2010 were reviewed. Epidemiological, clinical, therapeutical and evolutionary data were collected.

Results: At admission 45\% had severe deficits, percentage which improves throughout the evolution of the illness, with full recovery or minor deficits in the $87 \%$ of patients at the first year review. Ages greater than 55 years, severity at admission $(p<0.001)$, injured cranial nerves $(p=0.008)$ and the needing of ventilator support $(p=0.003)$ were associated with greater sequels at the discharge and at the posterior reviews in the following months. $17 \%$ required mechanical ventilation (MV). Values $<250 \mathrm{~L} / \mathrm{min}$ in the Peak Flow-test are associated with an increased likelihood of requiring MV $(p<0.001)$.

Conclusions: Older age, severe deficits at onset, injured cranial nerves, requiring MV, and axonal lesion patterns in the NCS were demonstrated as poor prognostic factors. Peak Flow-test is a useful predictive factor of respiratory failure by its easy management.
\end{abstract}

Keywords: Guillain-Barre, Natural history, Prognostic factors, Peak flow

\section{Background}

The term Guillain-Barré syndrome (GBS) includes a set of clinical syndromes (GBS) with a common pathophysiological basis; an acute inflammatory polyneuropathy with an autoimmune etiology [1-3]. Although usually characterized by a progressive flaccid paralysis with areflexia a wide range of motor, sensory and autonomic symptoms could be seen [1-4]. In general, the diagnosis is based on clinical criteria [4-7]; nevertheless, the presence of suggestive findings in the complementary test as demyelinising changes in the nerve conduction studies (NCS) or albuminocytological dissociation in the cerebrospinal fluid (CSF), help to confirm the diagnosis [1].

The worldwide incidence of GBS is reported to be 0.6-2.4 cases per 100,000 per year [8-15]. The classic form, the

\footnotetext{
* Correspondence: igonsua@gmail.com

${ }^{\dagger}$ Equal contributors

Section of Neuromuscular diseases, Department of Neurology, La Paz University Hospital, Paseo de la Castellana, Madrid 261.28046, Spain
}

acute inflammatory demyelinating polyradiculoneuropathy (AIDP), is the most frequent subtype in Europe, which accounts for $90 \%$ of GBS cases [2]. Other subtypes like the axonal forms or the Miller-Fisher syndrome (MFS) [16,17] are less common.

The prognosis is usually good, showing a complete functional recovery or with minimal deficits in the $90 \%$ of patients 1 year after the onset of illness [13,18]. Several factors have been identified as predictors of poor outcome $[13,14,19-21]$. Death rate is described to be between $1-18 \%[14,15]$. This study aimed to describe the epidemiological, clinical, laboratory, and electrodiagnostic features, as well as to identify the predictive factors of worse prognosis in the GBS or its subtypes.

\section{Methods}

A retrospective review of the medical records of patients admitted at La Paz University Hospital (Madrid, Spain)

\section{Biomed Central}


with the diagnosis of GBS between 2000-2010 was made. 106 fulfilled levels 1, 2 or 3 of diagnostic certainty for GBS/MFS described by Sejvar et al. [7]. All demographic, clinical, laboratory and electrophysiological data were recorded, as well as outcome and treatment.

Severity at admission was assessed by the Medical Research Council (MRC) sum score, valuing the strength from 0 to 5 in 4 muscles (proximal and distal) in both upper and lower limbs on both sides, so that the score ranged from 40 (normal) to 0 (quadriplegic) and by the GBS disability score advocated by Hughes et al. [22]. Cranial nerve involvement was considered separately by the affectation of oculomotor, facial and bulbar nerves. Respiratory weakness was assessed first by the value obtained at the peak expiratory flow meter (Peak Flow), as well as the need for mechanical ventilation throughout the evolution. Sensory disturbances, autonomic alteration or pain presence were also assessed.

Serological screening for preceding infections was recorded, including Herpes Simplex virus (HSV), VaricellaZoster (VZV), cytomegalovirus (CMV), Epstein-Barr virus (EBV), Mycoplasma Pneumoniae, B and C hepatitis virus, Haemophilus Influenzae and, in selected cases, stool and Campylobacter Jejuni determination. The CSF was analyzed for cell count, glucose and protein concentration.

Neurophysiological studies were evaluated in accordance with the criteria of Hadden et al. [23,24]. As in a retrospective study, not in all cases were the same nerves measured. Also, electromyography studies (EMG) with concentric needle electrodes were made to evaluate the axonal loss (fibrillation, positive sharp wave...).

The evaluation of the functional impact was graded by the GBS disability score [22] during the discharge from the neurology or the rehabilitation department, and at the third, sixth and twelfth month in the outpatient clinic.

The study was approved by the Research Ethics Committee of La Paz Hospital, Madrid, Spain.

All statistical analyses were performed using the SPSS 12 for Windows program (Chicago, IL, E.U.A.). For univariate analysis, Chi-square test for dichotomic variables was used. For continuous variables, t-Student test in parametric variables or U Mann-Withney with the non-parametric ones were used.

\section{Results}

There was no difference between genders (ratio male/ female 1.07), with a mean onset age of $43.7 \pm 23$ years (range 0-85). Demographic and clinical data are summarized in Table 1. There was a seasonal rebound in winter, when $41 \%$ of patients were diagnosed. Most patients had an infectious antecedent preceding the onset of the weakness, being the most frequent respiratory tract infection (38\%); at least 30\% did not present a previous infectious disease [25]. The mean of days since the start of
Table 1 Epidemiological data of GBS patients

\begin{tabular}{|c|c|c|}
\hline & Number of cases & $(\%)$ \\
\hline \multicolumn{3}{|l|}{ Gender } \\
\hline Male & 55 & 51.9 \\
\hline Female & 51 & 48,1 \\
\hline \multicolumn{3}{|l|}{ Age (years) } \\
\hline$<15$ & 15 & 14.2 \\
\hline $16-34$ & 24 & 22.6 \\
\hline $35-54$ & 28 & 26.4 \\
\hline$>55$ & 39 & 36.8 \\
\hline \multicolumn{3}{|l|}{ Antecedent events } \\
\hline Upper respiratory infection & 40 & 37.7 \\
\hline Gastrointestinal infection & 29 & 27.4 \\
\hline Vacunation & 2 & 1.9 \\
\hline Others & 3 & 2.8 \\
\hline None & 32 & 30.2 \\
\hline \multicolumn{3}{|l|}{ Season } \\
\hline Winter & 43 & 40.6 \\
\hline Spring & 20 & 18.9 \\
\hline Summer & 21 & 19.8 \\
\hline Autumn & 22 & 20.8 \\
\hline \multicolumn{3}{|l|}{ Motor deficit } \\
\hline Mild (MRC 31-40) & 60 & 56.6 \\
\hline Moderate (MRC 11-30) & 43 & 40.6 \\
\hline Severe (MRC 0-10) & 3 & 2.8 \\
\hline Cranial nerve involvement & 37 & 35.5 \\
\hline Facial palsy uni/bilateral & 27 & 25.5 \\
\hline MOE & 14 & 13.2 \\
\hline Bulbar nerves & 4 & 3.8 \\
\hline Ataxia & 8 & 7,5 \\
\hline \multicolumn{3}{|l|}{ Other symptoms } \\
\hline Sensory deficit & 31 & 29.2 \\
\hline Pain & 33 & 31.1 \\
\hline SNA & 9 & 8.5 \\
\hline SIADH & 7 & 6.6 \\
\hline Respiratory distress & 18 & 17 \\
\hline \multicolumn{3}{|l|}{ GBS disability score } \\
\hline Minor signs or symptoms & 12 & 11.3 \\
\hline Walk without support & 41 & 38.7 \\
\hline Walk with support & 16 & 15,1 \\
\hline Bedridden or chair bound & 19 & 17.9 \\
\hline Ventilated & 18 & 17 \\
\hline Death attributed to SGB & 2 & 1.9 \\
\hline
\end{tabular}


the infectious sickness until the polyneuropathy debut was $12 \pm 8.3$ days (range $1-30$ ).

\section{Clinical data}

A motor disorder at the admission was referred in 94 patients, with a variable degree. By classifying them according to the GBS disability score, 55\% retained the ability to walk (grades 1,2 and 3), unlike the remaining $45 \%$ which showed a severe affectation (grades 4, 5 and 6); Respiratory distress was present in $17 \%$ of patients. Pulmonary function was valued by the Peak Flow test in 50 patients, showed that values below $250 \mathrm{~L} / \mathrm{min}$ were associated with a greater likelihood of requiring MV during the income $(p<0.05)$, independently of the presence of uni/bilateral facial palsy $(\mathrm{p}<0.05)$. Time between symptom onset and admission was significantly lower in the severe cases (mean 5.17 days) compared with the mild ones (mean 8.87 days), so a faster progression could be postulated in the first ones $(p=0.053)$. Non-motor symptoms were described; the most frequent, neuropathic pain in $31 \%$ of patients, followed by sensory disturbances in $29 \%$. Autonomic dysfunctions were found in $8.5 \%$ of cases. In $7 \%$ of the patients a syndrome of inappropriate antidiuretic hormone hypersecretion (SIADH) was diagnosed [26].

\section{Laboratory and neurophysiological findings}

A lumbar puncture was made in 95 patients (90\%) with an average delay of $15 \pm 11.71$ days (range 1-80) since the beginning of symptoms. Raised concentration of proteins was present in 80 patients (85\%) with albuminocytological dissociation in 79 of them (85\%).

Serologic studies were made in 101 patients (95\%), in $8(8 \%)$ cases CMV was the microorganism responsible for the GBS; in 5 (5\%) Mycoplasma Pneumoniae, in 1 (1\%) EBV and 1 (1\%) enterovirus; the remaining $85.1 \%$ of serology was negative.
NCS was made in 98 patients (92.5\%) with a median period from the onset to the neurophysiological study of $20.73 \pm 10.17$ days (range 2-62). Resumed data of the neurophysiological test is shown in Table 2. In $57(58 \%)$ a demyelinating pattern was found, 7 (7\%) an axonal pattern, 3 (3\%) were unexcitable, 2 (2\%) were normal, and 29 (30\%) didn't fulfil diagnostic criteria for demyelinating lesion, but changes consistent with a peripheral neuropathy were present. Conduction blocks were present in 37 patients (37.8\%). F- Responses were altered (absent or delayed) in 29 of 64 median (45\%), in 16 of 35 ulnar (46\%) in 4 of 8 tibial (50\%) and in 34 of $40(85 \%)$ peroneal nerves. H-reflex was affected in 26 of 48 (45\%) cases evaluated. In sixth of the Miller Fisher syndromes a NCS was made, 1 of them (17\%) was normal, and in the remaining 5 (83\%) sensory conduction was affected. In 3 of $5(60 \%) \mathrm{H}$ reflex was absent. In the needle EMG examination signs of acute denervation were present in 44 of 86 (51\%).

The distribution of the different subtypes of GBS was: AIDP in 83\%, acute motor and sensory axonal neuropathy (AMSAN) in 5.7\%, acute motor axonal neuropathy (AMAN) in 1.9\%, MFS in $8.5 \%$ and cranial multineuritis in $0.9 \%$.

\section{Treatment, outcome and prognosis}

Some kind of treatment was offered to 89 patients (84\%): 88 received IVIg (83\%) and 3 plasma exchange (2.8\%); in 2 patients both treatments were dispensed sequentially. $16 \%$ of cases never started a treatment due to the mild symptoms or the long evolution of the disease.

At discharge, absent or minor deficits were observed in 38 patients (36\%), 30 (28\%) were able to walk for 10 meters without a help, 28 (26\%) needed assistance to walk, 7 (7\%) were bedridden and 1 (1\%) needed respiratory support. Two patients died of the disease. Patients were followed in the outpatient clinic at 3, 6 and 12 months (Table 3).

Table 2 Neurophysiological data of patients with GBS

\begin{tabular}{|c|c|c|c|c|c|c|c|c|}
\hline & $\mathrm{N}$ & CMAP (mV) & MDL (ms) & $\operatorname{MCV}(\mathrm{m} / \mathrm{s})$ & $\mathrm{n}$ & SNAP $(\mu \mathrm{V})$ & $\mathrm{DL}(\mathrm{ms})$ & $\mathrm{SCV}(\mathrm{m} / \mathrm{s})$ \\
\hline Median & 83 & $6,8 \pm 5,6$ & $6,4 \pm 7,8$ & $43,6 \pm 17,9$ & 85 & $7,03 \pm 7,8$ & $3,2 \pm 3,4$ & $43,6 \pm 16,6$ \\
\hline Min-Max & & $0,07-21,30$ & $0,1 \pm 61,0$ & $0,10 \pm 65,5$ & & $0,1-43,2$ & $0,1-27,7$ & $0,1-63,4$ \\
\hline Ulnar & 32 & $8,0 \pm 7,8$ & $3,4 \pm 1,5$ & $46,6 \pm 17,4$ & 72 & $3,9 \pm 3,9$ & $2,6 \pm 1,9$ & $43,2 \pm 16,4$ \\
\hline Min-Max & & $0,1-16,6$ & $0,1-7,5$ & $0,1-8,1$ & & $0,1-19,9$ & $0,1-14,2$ & $0,1-59,7$ \\
\hline Tibial post & 14 & $4,8 \pm 5,9$ & $6,7 \pm 2,2$ & $33,5 \pm 15,6$ & & & & \\
\hline Min-Max & & $0,2-18,10$ & $4,0-11,0$ & $0,1-50,20$ & & & & \\
\hline Peroneal & 87 & $3,6 \pm 3,9$ & $6,9 \pm 5,1$ & $35,9 \pm 14,8$ & & & & \\
\hline Min-Max & & $0,1-15,7$ & $0,1-31,4$ & $0,1-54,1$ & & & & \\
\hline Sural & & & & & 71 & $6,01 \pm 5,4$ & $2,6 \pm 1,9$ & $39,2 \pm 15,5$ \\
\hline Min-Max & & & & & & $0,1-27,4$ & $0,1-18,0$ & $0,1-57,2$ \\
\hline Sup Peroneal & & & & & 39 & $9,7 \pm 8,2$ & $2,2 \pm 0,7$ & $39,8 \pm 12,7$ \\
\hline Min-Max & & & & & & $0,1-37,4$ & $0,1-3,8$ & $0,13-8$ \\
\hline
\end{tabular}


Table 3 Proportion of patients, based on the GBS score, during the follow-up

\begin{tabular}{|c|c|c|c|c|c|c|c|c|}
\hline & & & 3th & vision & 6th & vision & $12 \mathrm{t}$ & vision \\
\hline & $\mathrm{N}$ & (\%) & $\mathrm{N}$ & $(\%)$ & $\mathrm{N}$ & $(\%)$ & $\mathrm{N}$ & (\%) \\
\hline Healthy & 4 & 3,8 & 18 & 29,5 & 17 & 36,2 & 18 & 58,1 \\
\hline Minor deficits or symptoms & 34 & 32,1 & 19 & 31,1 & 15 & 31,9 & 7 & 22,6 \\
\hline Walk without support & 30 & 28,3 & 14 & 23 & 8 & 17 & 2 & 6,5 \\
\hline Walk with support & 28 & 26,4 & 10 & 16,4 & 7 & 14,9 & 4 & 12,9 \\
\hline Bedbridden or chairbound & 7 & 6,6 & 0 & & 0 & & 0 & \\
\hline Ventilated & 1 & 0,9 & 0 & & 0 & & 0 & \\
\hline Death & 2 & 1,9 & 0 & & 0 & & 0 & \\
\hline
\end{tabular}

Some factors were analysed as possible predictors of a poor outcome: 1) patients with ages greater than 55 years were most affected at the admission $(p=0.027)$, with greater deficits at discharge $(\mathrm{p}=0.2)$ and at the third $(\mathrm{p}=0.1)$, sixth $(\mathrm{p}=0.001)$ and twelfth month $(\mathrm{p}=0.006) ; 2)$ severity at admission, score based on the GBS disability scale (disabling or non-disabling), was also associated with more disability at discharge $(\mathrm{p}<0.001)$, and at the successive medical reviews at the third $(\mathrm{p}=0.001)$ and the sixth month ( $<0.001)$; 3$)$ cranial nerve involvement was related with greater deficits at discharge $(\mathrm{p}=0.008)$ and 4$)$ mechanical ventilation requirement showed greater sequels at discharge ( $p=0.003)$, in the follow up the results were not statistically significant but a trend to associate with greater deficits was seen. Finally, there seems to be a trend towards a worse prognosis in those patients with axonal lesions in the conduction studies $(\mathrm{p}=0.2)$ which is likely to be maintained throughout the evolution (Table 4).

\section{Discussion}

The present work has the limitations of a retrospective study based on hospital case-mix. The incidence is reported to be $0.6-2.4$ cases per 100,000 per year $[18,19,21]$. Changes suffered in the last years in the attendance area of the hospital make incidence calculation complex and inaccurate; however, it appears to be of $1.68-2.46$ per 100,000 per year.

There is no difference between gender $[1,2]$. The bimodal shape wasn't present in our study [8-10], as there is a linear increase in the incidence with age $[1,2,9,11,12,24]$. GBS is considered a sporadic illness, without a seasonal cluster $[1,9]$; however, a trend to accrue in winter is shown in our series $[11,12]$. The infectious event is described to appear in $40-70 \%$ of patients $[1-3,8-12]$. In our series up to $70 \%$ of cases have had one, of which respiratory infection was the most frequent.

As in previous series, weakness and hypo/areflexia were the most frequent symptoms, followed by neuropathic pain and numbness. Hyponatremia, as a symptom of SIADH is not a classical manifestation of GBS; however, there are series in which are described to be present in up to $58 \%$ of the cases; in our review, it was found in $7 \%$ of our patients.

There isn't a consensus about the neurophysiological values defining GBS and its variants [2,4,5,7,23,24,26-29].

Table 4 Possible predictor factors of a poor outcome

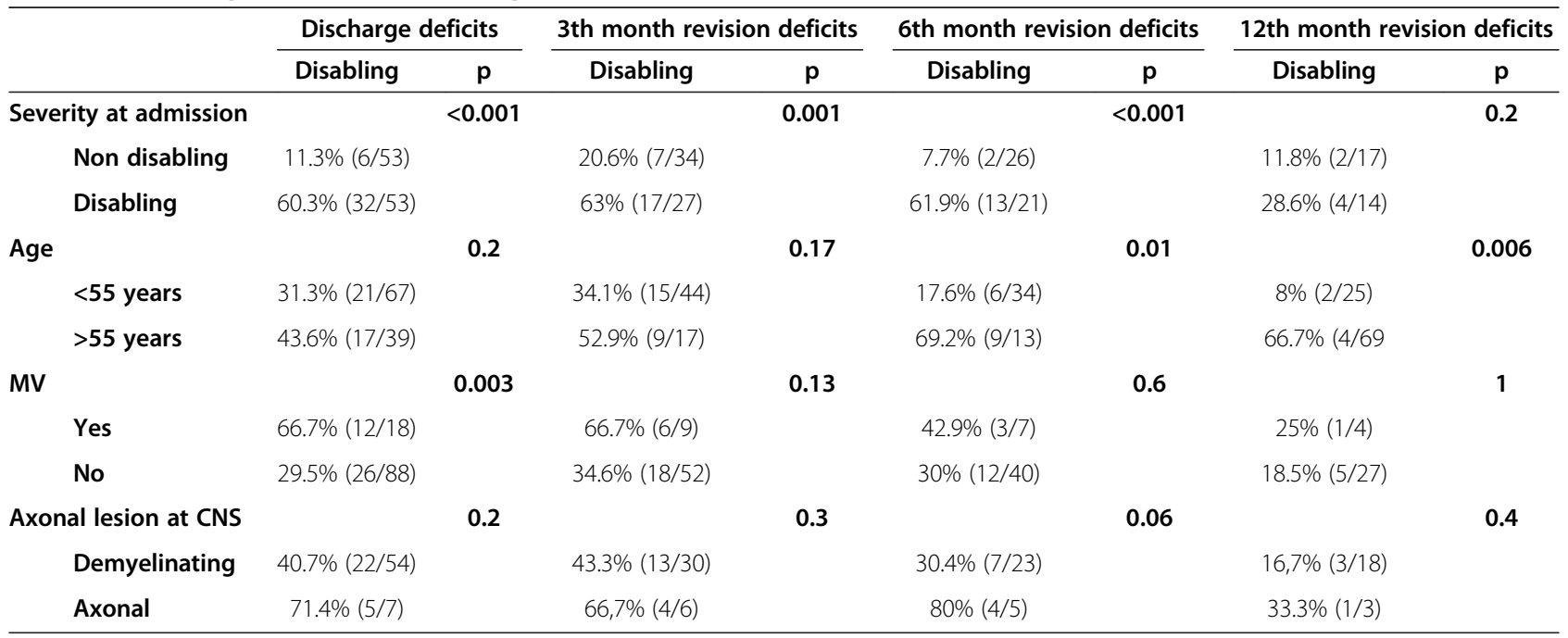

Statistical analysis of the disabling deficits and the possible poor prognostic factors during the follow-up. 
It is accepted as demyelination parameters: motor conduction velocity $(\mathrm{MCV})$ decrease, prolongation of motor distal latency, conduction blocks, temporal dispersion and increased F-wave latency [27]. It is reported that the first electromyographic changes are the alteration of $\mathrm{F}$-wave and H-reflex response [2,22], altered both in our NCS reported as normal, probably due to the earliness of the exploration. In MFS, the CNS are normal in most cases; nonetheless, discrete changes in the sensory conduction or in H-reflex may be present [30-32], some authors postulate a damage in the afferent proprioceptive system as a pathophysiological basis [32].

As classically described, in our study illness prognosis is favourable; $81 \%$ of patients presented absent or minimum neurological deficits one year after the onset. Older age, illness severity in the acute phase, prior gastrointestinal infection and axonal injury in the CNS and mechanical ventilation requirement $[15,20,33,34]$ are among the factors that have been advocated for poor prognosis. Van Koningsveld et al. defined a clinical prognostic scoring system for GBS outcome at 6 months, the "Erasmus GBS Outcome Score" or EGOS [15], it was based on the punctuation on the GBS disability score at 2 weeks from the admission, the history of diarrhoea and the age. Recently, Walgaard et al. have validated a modified EGOS (mEGOS) with the main difference being the use of the MRC sum score at admission and in the 7th day instead the GBS disability score [35], they claimed that the MRC sum score is more accurate, and the possibility of being used at admission could predict the future treatments. However, the mEGOS made on the 7th day after the admission show increased predictive value instead the one made on the first day [35]. However, although useful, the mEGOS passed on the first day of admission showed lower predictive ability than the one performed on the 7th day. In our study we demonstrate that, even in the first day of admission, lower scores on the GBS scale are associated with worse outcome and greater disability at discharge, 3 and 6 months. Respiratory distress is the leading cause of death in the acute phase, 20-30\% requiring ventilatory support [20]. Many factors have been proposed as predictors of the future need for respiratory support, like forced vital capacity $(\mathrm{FVC})<60 \%$, bulbar dysfunction, rapid progression of the illness, and difficulty raising the head [19,20]. Van Doorn et al. propose a regularly monitoring of the respiratory function initially every $2-4 \mathrm{~h}$, and then every $6-12 \mathrm{~h}$ [1]. Although FVC is considered to be the gold standard test for detecting impaired ventilation it has some disadvantages, the requirement of portable spirometers in the acute phase due to the instability of the patient, the need for a minimum of preparation and knowledge of the technique by medical personnel and the higher cost. Suárez et al. describe a serie of 79 patients with neuromuscular diseases in which the Peak Flow test proved to be useful in the monitoring of expiratory muscle weakness [35]. In our hospital, patients were monitored by the Peak Flow test each 6 hours in the acute phase, being observed that values below $250 \mathrm{~L} / \mathrm{min}$ predict the posterior need of respiratory support $(\mathrm{p}<0.05)$, independently of the presence of facial palsy that could hinder the use of the test $(\mathrm{p}<0.05)$, making the Peak Flow a safe, inexpensive, and widely-available test in the monitoring of patients with GBS.

\section{Conclusion}

Our series is in concordance with those previously published. The seasonal cluster in winter is worth noting on which there is a great controversy. Regarding the outcome, our series reported a worse prognosis in patients with older age, severe deficits at the beginning, injured cranial nerves, requiring MV, and axonal lesion patterns in the NCS. Finally, project the Peak Flow-test as a useful predictive factor of respiratory failure by its availability, and easy management.

\section{Abbreviations}

AIDP: Acute inflammatory demyelinating Polyradiculoneuropathy; AMAN: Acute motor axonal neuropathy; AMSAN: Acute motor and sensory axonal neuropathy; CB: Conduction blocks; CMAP: Conduction motor action potential; CMV: Cytomegalovirus; CSF: Cerebrospinal fluid; EBV: Ebstein-Barr virus; EMG: Electromyography studies; GBS: Guillain-Barré syndrome; HSV: Herpes-simplex virus; IVlg: Immunoglobulin; MRC: Medical research council; MFS: Miller-Fisher syndrome; MV: Mechanical ventilation; NCS: Nerve conduction studies; SIADH: Syndrome of inappropriate antidiuretic hormone hypersecretion; VZV: Varicella-Zoster virus.

\section{Competing interests}

There are no competing interests in this manuscript.

\section{Authors' contributions}

IGS conceived of the study, participated in the design of the study and performed the statistical analysis, and coordination and drafted the manuscript. ISG participated in the design of the study. FJRR participated in the design of the study. JA conceived of the study, participated in the design of the study and coordination and drafted the manuscript. All authors read and approved the final manuscript.

\section{Acknowledgements}

Our thanks are due to Mr. Martin J. Smyth, B.A. for correcting the English.

Received: 20 March 2012 Accepted: 11 July 2013

Published: 22 July 2013

\section{References}

1. Van Doorn PA, Ruts L, Jacobs BC: Clinical features, pathogenesis, and treatment of Guillain-Barré syndrome. Lancet Neurol 2008, 7:939-950.

2. Vucic S, Kiernan MC, Cornblath DR: Guillain-Barré syndrome: An update. J Cli Neurosci 2009, 16:733-741.

3. Tellería-Díaz A, Calzada-Sierra DJ: Síndrome de Guillain-Barré. Rev Neurol 2002, 34(10):966-976.

4. Asbury AK, Arnason BGW, Karp HR, McFarlin DF: Criteria for diagnosis of Guillain-Barré syndrome. Ann Neurol 1978, 3:565-566.

5. Asbury AK, Cornblath DR: Assesment of current diagnostic criteria for Guillain-Barré syndrome. Ann Neurol 1990, 27(Suppl):S21-S24.

6. Hughes RAC, Rees JH: Clinical and epidemiologic features of Guillain-Barr é syndrome. J Infect Dis 1997, 176(suppl2):S92-S98.

7. Sejvar JJ, Kohl KS, Gidudu J, Amato A, Bakshi N, Baxter R, et al: Guillain-Barré syndrome and Fisher syndrome: case definitions and guidelines for 
collection, analysis, and presentation of immunization safety data. Vaccine 2011, 29:599-612.

8. McGrogan A, Madle G, Seaman HE, De Vries CS: The epidemiology of Guillain-Barré syndrome worldwide. Neuroepidemiology 2009, 32:150-163.

9. The Emilia-Romagna Study group on Clinical and Epidemiological Problems in Neurology: A prospective study on the incidence and prognosis of Guillain-Barré syndrome in Emilia-Romagna region, Italy (1992-1993). Neurology 1997, 48:214-221.

10. Lyu R-K, Tang L-M, Cheng S-Y, Hsa W-C, Chen S-T: Guillain-Barré syndrome in Taiwan: a clinical study of 167 patients. J Neurol Neurosurgery Psychiatry 1997, 63:494-500

11. Cuadrado Jl, de Pedro Cuesta J, Ara JR, Cemillan CA, Díaz M, Duarte J, et al: Guillain-Barré syndrome in Spain, 1985-1997: epidemiological and public health view. Eur Neurol 2001, 46:83-91.

12. Alandro-Benito $Y$, Conde-Sendín MA, Muñoz-Fernández C, Pérez-Correa $S$, Alemany-Rodríguez MJ, Fiuza-Pérez MD, et al: Síndrome de Guillain-Barré en el área norte de Gran Canaria e isla de Lanzarote. Rev Neurol (Barc.) 2002, 35:705-710.

13. Soysal A, Aysal F, Caliskan B, Dogan Ak P, Mutluay B, Sakalli N, et al: Clinico-electrophysiological findings and prognosis of Guillain-Barré syndrome - 10 years'experience. Acta Neurol Scand 2011, 123:181-186.

14. The Italian Guillain-Barré Study Group: The prognosis and main prognostic indicators of GuillainBarré syndrome. A multicentre prospective study of 297 patients. Brain 1996, 119:2053-2061.

15. Van Koningsveld R, Steyerberg EW, Hughes RAC, Swan AV, Van Doorn PA, Jacobs BC: A clinical prognostic scoring system of Guillain-Barré syndrome. Lancet Neurol 2007, 6:589-594.

16. Chodwury D, Arora A: Axonal Guillain Barré syndrome: a critical review. Acta Neurol Scand 2001, 103:267-277.

17. Mori M, Kuwaraba S, Fukutake T, Yuki N, Hattori T: Clinical features and prognosis of Miller Fisher syndrome. Neurology 2001, 56:1104-1106.

18. Korinthenberg R, Schessl J, Kirschner J: Clinical presentation and course of childhood Guillain-Barré syndrome: a prospective multicentre study. Neuropediatrics 2007, 38:10-17.

19. Lawn ND, Fletcher DD, Henderson RD, Wolter TD, Wijdicks EF: Anticipating mechanical ventilation in Guillain-Barré syndrome. Arch Neurol 2001, 58:871-872.

20. Durand MC, Porcher R, Orlikowski D, Aboab J, Devaux C, Clair B, et al: Clinical and electrophysiological predictors of respiratory failure in Guillain-Barré syndrome: a prospective study. Lancet Neurol 2006, 5:1021-1028.

21. Ropper AH, Widjicks EFM, Truax BT (Eds): Guillain- Barré syndrome. Philadelphia: F.A. Davis; 1991.

22. Hughes RA, Newsom-Davis JM, Perkin GD, Pierce JM: Controlled trial prednisolone in acute polineuropathy. Lancet 1978, 2:750-753.

23. Hadden RDM, Cornblath DR, Hughes RAC, Zielasek J, Hartung HP, Toyka K, et al: Electrophysiological classification of Guillain-Barré Syndrome: clinical associations and outcome. Ann Neurol 1998, 44:780-788.

24. Hughes RAC, Cornblath DR: Guillain-Barré syndrome. Lancet Neurol 2005, 366:1653-1666.

25. Hadden RD, Karch H, Hartung HP, Zielasek J, Weissbrich B, Schubert J: Preceding infections, immune factors, and outcome in Guillain-Barré syndrome. Neurology 2001, 56:758-765.

26. Saifudheen K, Jose J, Gafoor VA, Musthafa M: Guillain-Barré síndrome and SIADH. Neurology 2011, 76:701-704.

27. Van den Bergh PYK, Piéret F: Electrodiagnostic criteria for acute and chronic inflammatory demyelinating polyradiculoneuropathy. Muscle Nerve 2004, 29:565-574.

28. Vucic S, Cairns KD, Black KR, Chong PST, Cros D: Neurophysiologic findings in early acute inflammatory demyelinating polyradiculoneuropathy. Clin Neurophysiology 2004, 115:2329-2335.

29. Alam TA, Chaudhry V, Cornblath DR, Electrophysiological studies in the Guillain-Barré syndrome: 30, Alam TA, Chaudhry V, Cornblath DR: Electrophysiological studies in the Guillain-Barré syndrome: distinguishing subtypes by published criteria. Muscle Nerve 1998, 21:1275-1279

30. Jamal GA, Leod Mac WN: Electrophysiologic studies in Miller Fisher syndrome. Neurology 1984, 34:685-688.

31. Lo YL: Clinical and immunological spectrum of the Miller Fisher syndrome. Muscle Nerve 2007, 36:615-627.

32. Yuki N: Fisher syndrome and Bickerstaff brainstem encephalitis (Fisher-Bickerstaff syndrome). J Neuroimmunol 2009, 215:1-9.
33. Rajabally YA, Unicini A: Outcome and its predictors in Guillain-barré syndrome. J Neurol Neurosurg Psychiatry 2012, 83:711-718.

34. Walgaard C, Lingsma HF, Ruts $L$, et al: Early recognition of poor prognosis in Guillain-Barré syndrome. Neurology 2011, 76:968-975.

35. Suarez AA, Pessolano FA, Monteiro SG, Ferreyra G, Capria ME, Mesa L, et al: Peak flow and peak cough flow in the evaluation of expiratory muscle weakness and bulbar impairment in patients with neuromuscular disease. Am J Phys Med Rehabil 2002, 81:506-511.

doi:10.1186/1471-2377-13-95

Cite this article as: González-Suárez et al:: Guillain-Barré Syndrome: Natural history and prognostic factors: a retrospective review of 106 cases. BMC Neurology 2013 13:95.

\section{Submit your next manuscript to BioMed Central and take full advantage of:}

- Convenient online submission

- Thorough peer review

- No space constraints or color figure charges

- Immediate publication on acceptance

- Inclusion in PubMed, CAS, Scopus and Google Scholar

- Research which is freely available for redistribution
() Biomed Central 